\title{
Quality Parameters, Nitrogen Content and Uptake of Cotton Cultivar H-1098(i) and Nutrient Status of Soil Influence by Different Spacing and Nitrogen Application
}

\author{
Kapil Malik* , A. K. Mehta and S. K. Thakra \\ Department of Agronomy, CCS Haryana Agricultural University, \\ Hisar-125004, Haryana, India \\ *Corresponding author
}

\section{A B S T R A C T}

Keywords

Cotton, GOT, Uptake, Spacing, Nitrogen, Seed index, Fiber length and Nutrient status

Article Info

Accepted:

20 December 2020 Available Online: 10 January 2021
An experimental research was performed at cotton research station at Sirsa district, CCS Haryana Agricultural University, Hisar during kharif to evaluate the different spacing and dose of nitrogen influences on quality and nutrient quality of cotton. The experimentation was laid out in split plot design having 4 spacing in main plots and 4 nitrogen doses in sub plots with 3 replications. The soil of the research field was loamy sand in texture with low nitrogen status. The trial results revealed that the nitrogen content in plant as well as in seed was also not affected by plant spacing however, uptake of nitrogen in seed was maximum with $67.5 \mathrm{~cm} \times 15 \mathrm{~cm}$ spacing while nitrogen uptake in plant and total uptake was maximum in $67.5 \mathrm{~cm} \times 10 \mathrm{~cm}$ spacing. Nitrogen content in seed increased significantly with $100 \%$ RD of nitrogen over $75 \%$ RD of nitrogen which remained at par with further increase in nitrogen levels however, nitrogen content in plant did not differ significantly with different nitrogen rates. The uptake of nitrogen in seed and plant as well as total uptake increased significantly up to application of $125 \% \mathrm{RD}$ of nitrogen. The available nitrogen in soil was higher in $67.5 \mathrm{~cm} \times 30 \mathrm{~cm}$ spacing. However, no significant variation in available $\mathrm{P}$ and $\mathrm{K}$ in soil was attained in different spacing treatments. Similarly, available $\mathrm{N}$ in soil after harvest of crop differed significantly under nitrogen levels, but it had no significant effect on available $\mathrm{P}$ and $\mathrm{K}$ in soil. The quality characters like ginning out turn (GOT), fiber length, micronaire value, and seed index were not affected significantly by different crop geometry and nitrogen levels.

\section{Introduction}

Cotton crop is one the most important commercial fibre crop also known as "white gold" grown all over the world. Cotton plant is shrubby, or tree-like cultivated in tropical and subtropical regions in India. It is perennial crop, but most of the cotton variety cultivated today has been developed into annuals. The plant height of cotton ranges from 2-6 feet, spiral arranged leaves, and main stem is erect having two branches (monopodial or vegetative type and sympodial or fruiting branches) with tap root system. The cotton inflorescence consists of solitary flowers which appear at the nodes 
opposite to leaf in sympodial branches. It can tolerate high temperature up to $45-46^{\circ} \mathrm{C}$ but below $25^{\circ} \mathrm{C}$ temperature is not suitable for cotton. The temperature between $27^{\circ} \mathrm{C}$ and $32^{\circ} \mathrm{C}$ is optimum for boll development and maturation but temperature reaches above $38^{\circ} \mathrm{C}$ cause yield reduction of cotton crop. Cotton is regarded as a foremost agricultural commodity sustaining Indian economy. Cotton provides a livelihood to more than sixty million citizens by way of engaging in agriculture, processing and textiles industry. Cotton is also used for preparation of edible oil from its seeds (16-24\%). Like, cotton is grow for fibre purposes for making the fabric clothes in the industry but now a days, increasing population and enhancing income status of people, the demand of raw material of cotton is lift up therefore, there is urgent need to augment the production of cotton. To overcome this problem, superlative agronomic interventions are required to fully conquer the yield potential of any genotypes. The best option is to focus more on managing spacing distance between plants. Appropriate crop geometry helping individual plant to establish better and provide favorable microclimate to plants in a specific portion of field area. Optimum plant spacing favors seed cotton yield by influencing plant population and physique of plants (Jagtap, 2008). Secondly, imbalanced use of fertilizer or less dose of fertilizer also distresses the vegetative and reproductive growth of plants. Cotton yield, quality and nutrient concentration are varied with different fertilizer dose under different spacing (Sharma et al., 2001; Dhillon et al., 2006). Cotton performs healthier to higher doses of fertilizers particularly nitrogen but the response may not always be in the form of seed cotton yield. However, response may be in form of production of vegetative parts such as plant height (Ahmad et al., 2009; Jat et al., 2014) and leaves count but, under limited supply of nitrogen, fiber fails to develop its full extent consequences into poor quality and also induce premature senescence leading to potential yield loss. Accordingly, observing the struggle between plants for plant nutrients, it is crucial to unearth the suitable combination of spacing and nitrogen dose (Malik et al., 2019). Nitrogen is vital and imperative nutrient for obtaining higher yield and quality of cotton crop need to supply at proper quantity and time (Paslawar et al., 2014). The production output of cotton improves under proper spacing condition and fertilizer application. Therefore, it is indispensable to familiar with agronomical practices such as acceptable spacing and nitrogen doses to save the cost and boost the productivity, improve the quality and enhance the nutrient content. Keeping above aspects in mind, an experimental was laid out to study the influence of different spacing and nitrogen application on quality parameters, nitrogen content and uptake of cotton and nutrient status of soil.

\section{Materials and Methods}

The field investigation was carried out during kharif season (2015) at cotton research station, Sirsa, Chaudhary Charan Singh Haryana Agricultural University, Hisar, Haryana (India). Sirsa is located $29^{\circ} 25^{\prime} \mathrm{N}$ latitude, $74^{\circ} 40^{\prime} \mathrm{E}$ longitude and at an altitude of 202 meters above mean sea level (msl). It lies in sub-tropical region of north western India, in the state of Haryana. The all weather parameters were favorable for the crop recorded Central Institute of Cotton Research (CICR), Sirsa. Representative soil samples were randomly collected from five places at a depth of $0-15 \mathrm{~cm}$ and $15-30 \mathrm{~cm}$ from the experimental field before sowing of crop to know the physico-chemical properties of the soil. The composite soil samples were subjected to mechanical and chemical analysis. The soil properties prevailing before sowing of crop are depicted in table 1. 
The soil of field before sowing was loamy sand in texture. Chemical properties of the soil was normal with respect to electrical conductivity, slightly high in $\mathrm{pH}$, low in organic carbon and available nitrogen, and medium in available phosphorus and high in

\begin{tabular}{|l|l|l|l|}
\hline Design & Split plot design & Treatment combinations & $4 \times 4=16$ \\
\hline Variety & H-1098 (i) & Replications & 3 \\
\hline Gross plot size & $5.4 \times 6.3 \mathrm{~m} 2$ & Total number of plots & 48 \\
\hline
\end{tabular}

The cultural operations such as tillage practices, thinning, hoeing, weeding, irrigation and plant protection measures were performed as per university guidelines however, during sowing, seed were buried deep at depth of $5 \mathrm{~cm}$ by hand dibbing according to spacing treatments and in fertilizer application, treatment wise nitrogen (N) dose was given (half at squaring stage; half at flowering stage) through urea while full dose of phosphorus (P) was applied through di-ammonium phosphate (DAP). The reading of ginning out turn (\%) was measured by taking $100 \mathrm{~g}$ sample of kapas from the each plot was taken and ginned to get lint and seed and then GOT was calculated by the following formula.

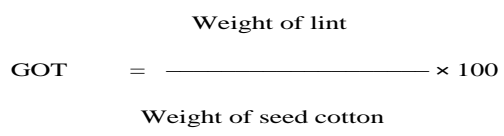

And the fibre length is termed as distance spanned by a specified percentage of fibers in the specimen being tested when the fibers are paralyzed and randomly distributed The most commonly used measure is the 2.5 percent span length, which is the measure of fiber length and is tested using high volume instrument and fibre length is expressed in 'mm'. Whereas, Fibre fineness is the measure of fibre weight in mg per unit length of fibre and it was determined by using micronaire but recently measured by high volume instrument (HVI). It gives the resistance by the fiber to available potash. The experiment was laid out in Split Plot Design having four spacing's in main plots and four nitrogen doses in sub plots with three replications. The layout of experiment field is presented in Fig. 1. the flow of air and the value is termed as micronaire value. It is determined by micronaire instrument in which $50 \mathrm{~g}$ of the sample is taken and compressed in a cylinder of specified dimension. Air at specific pressure is passed through the material. The amount of airflow is measured on a scale calibrated directly to read the weight per unit length of the fiber. Finer cottons have lower micronaire value. The seed index reading was worked out by taking weight of 100 seeds (g) from each net plot after ginning. It ensures evaluation of properly developed seeds and leads to development of lint index.

For determining the nitrogen content, plant sample $(0.5 \mathrm{~g}$ each) was digested in diacid mixture of $\mathrm{H}_{2} \mathrm{SO}_{4}$ and $\mathrm{HClO}_{4} \quad(9: 1)$ to determine total nitrogen content. Nessler's reagent was used in this calorimetric procedure from which orange coloured complex $\mathrm{Hg}_{2} \mathrm{O}$ (NH2I) was obtained. Intensity of this orange coloured complex was measured in spectrophotometer at $420 \mathrm{~nm}$ by using blue filter. The uptake was computed by multiplying the nitrogen content with plant biomass.

$\mathrm{N}$ content $(\%) \times$ Yield $\left(\mathrm{kg} \mathrm{ha}^{-1}\right)$

$\mathrm{N}$ Uptake $\left(\mathrm{kg} \mathrm{ha}^{-1}\right)=$

100

For calculating the available nitrogen from soil, it was estimated by alkaline permanganate method of Subbiah and Asija (1956). The easily oxidizable organic nitrogen present in the soil was oxidized by potassium 
permanganate in the presence of $\mathrm{NaOH}$ by distillation. During oxidation, the released ammonia was absorbed in boric acid to convert the ammonia to ammonium borate, which was titrated with the standard sulphuric acid. Whereas, the Olsen's method was used for determining available $\mathrm{P}$ in soil in which phosphorus was extracted from the soil using $0.5 \mathrm{M}$ sodium bicarbonate $\left(\mathrm{NaHCO}_{3}\right), \mathrm{pH} 8.5$ as an extractant. Phosphorus was estimated colorimetrically by adding ammonium molybdate to aliquot and reducing the molybdenum phosphate complex in acidic medium. The intensity of blue colour was read on colorimeter using $660 \mathrm{~nm}$ red filters. However, available potassium i.e. exchangeable and water soluble $\mathrm{K}$ in soil was determined in neutral normal ammonium acetate $\left(\mathrm{NH}_{4} \mathrm{OAC}\right)$ extract of soil. Shaking followed by filtration carried out the extraction and the potassium in extract was estimated by using flame photometer (Jackson, 1973). Data collected during the study were statistically analyzed by using the technique of analysis of variance (ANOVA) described by Cochran and Cox (1963). To judge the significant difference between means of two treatments, the critical difference (C.D) was worked out using following formula:

C.D $=(\sqrt{ } 2 \times E M S / n) \times t$ value at $5 \%$

Where,

C.D $=$ critical difference

EMS $=$ error mean sum of square

$\mathrm{n}=$ number of observations

$\mathrm{t}=$ value of $\mathrm{t}$-distribution at $5 \%$ level of significance \& error degree of freedom

\section{Results and Discussion}

\section{Quality parameters}

The data pertaining to ginning out turns, fibre length, micronaire value and seed index were present in table 2 . The experimental result showed that the all quality parameters (G.O.T (\%), fibre length $(\mathrm{mm})$, and micronaire value $\left(10^{-6} \mathrm{~mm}\right.$ inch $\left.^{-1}\right)$, and seed index $\left.(\mathrm{g})\right)$ were not affected significantly by different crop geometry and nitrogen doses. But, there was an increasing trend in ginning out turn, fibre length and seed index with increasing various spacing and nitrogen doses. Because quality characters of crop depends upon genetic and environmental factors. Hence variations in quality parameters were not observed significantly. The results are in confirmity with those noted earlier by Ahmad et al., 2009; Shekar et al., 2012; Jat et al., 2014; Bharathi et al., 2012 and Paslawar et al., 2014.

\section{Nitrogen content and uptake}

Nitrogen content and uptake in seed and plant as influenced by different treatments has been presented in table 3. The result indicated that various spacing did not affect nitrogen content in seed significantly. However, nitrogen uptake in seed was significantly influenced all the geometry treatments and maximum uptake was found in $67.5 \mathrm{~cm} \times 15$ $\mathrm{cm}$ spacing as compared to $67.5 \mathrm{~cm} \times 22.5 \mathrm{~cm}$ and $67.5 \mathrm{~cm} \times 30 \mathrm{~cm}$ but at par with spacing of $67.5 \mathrm{~cm} \times 10 \mathrm{~cm}$. The uptake of nutrients is a product of dry matter accumulation and nutrient concentration. Closer spacing of 67.5 $\mathrm{cm} \times 10 \mathrm{~cm}$ recorded maximum total uptake of nitrogen by crop followed by $67.5 \mathrm{~cm} \times 15$ $\mathrm{cm}, 67.5 \mathrm{~cm} \times 22.5 \mathrm{~cm}$ and $67.5 \mathrm{~cm} \times 30 \mathrm{~cm}$. The higher uptake of nitrogen recorded with higher plant population also reported by Dhillon et al., (2006) and Devraj et al., (2011).

Under different nitrogen doses, the nitrogen content in seed was statistically influenced. It was increased significantly with $100 \%$ RD of nitrogen over $75 \% \mathrm{RD}$ of nitrogen but 
remained at par with further increase in nitrogen levels. Nevertheless, nitrogen uptake in seed increased significantly with increasing levels of nitrogen up to $125 \% \mathrm{RD}$ and thereafter it remained statistically at par with further increase in nitrogen levels i.e. $150 \%$ $\mathrm{RD}$ of nitrogen. Whereas, data related to nitrogen content in plant which was not affected by different spacing and nitrogen doses. While, nitrogen uptake was significantly higher in plant in the spacing of $67.5 \mathrm{~cm} \times 10 \mathrm{~cm}$ as compare to rest of spacing and lowest uptake was recorded by wider spacing $(67.5 \mathrm{~cm} \times 30 \mathrm{~cm})$. In relation to nitrogen doses, as increased in nitrogen levels upto125\% RD of nitrogen, $\mathrm{N}$ uptake in plant increased significantly.

Table.1 Physico-chemical analysis of experiment field before sowing of cotton crop

\begin{tabular}{|c|c|c|c|}
\hline \multirow[t]{2}{*}{ Soil property } & \multicolumn{2}{|c|}{ Soil depth $(\mathrm{cm})$} & \multirow[t]{2}{*}{ Method of determination } \\
\hline & 0-15 & $15-30$ & \\
\hline Sand $(\%)$ & 73.3 & 75.7 & International pipette method (Piper, 1966) \\
\hline Silt $(\%)$ & 16.5 & 13.8 & \\
\hline Clay $(\%)$ & 10.2 & 10.5 & \\
\hline pH (1:2, soil: water suspension) & 8.5 & 8 & $\begin{array}{l}\text { pH meter with glass electrode in 1:2 soil water } \\
\text { suspension (Jackson, 1973) }\end{array}$ \\
\hline $\begin{array}{l}\text { Electrical conductivity }\left(\mathrm{dS} \mathrm{m}^{-1}\right. \\
\left.\text { at } 25^{\circ} \mathrm{C}\right)\end{array}$ & 0.56 & 0.6 & $\begin{array}{l}\text { Conductivity bridge meter 1:2 soil-water } \\
\text { suspension (Richards, 1954) }\end{array}$ \\
\hline Organic carbon $(\%)$ & 0.35 & 0.29 & $\begin{array}{l}\text { Walkley and Black rapid titration method } \\
\text { (Jackson,1973) }\end{array}$ \\
\hline Available N (kg ha $\left.{ }^{-1}\right)$ & 137 & 133 & $\begin{array}{l}\text { Alkaline potassium permanganate method } \\
\text { (Subbiah and Asija, 1956) }\end{array}$ \\
\hline \multirow[t]{2}{*}{ Available $\mathbf{P}\left(\mathrm{kg} \mathrm{ha}^{-1}\right)$} & 13.4 & 10.8 & $0.5 \mathrm{~N}$ sodium bicarbonate method \\
\hline & & & (Olsen et al, 1954) \\
\hline \multirow[t]{2}{*}{ Available K (kg ha $\left.{ }^{-1}\right)$} & 413 & 409 & Ammonium acetate extraction method \\
\hline & & & (Jackson, 1973) \\
\hline
\end{tabular}

Table.2 Effect of different spacing and nitrogen application on quality parameters of cotton

\begin{tabular}{|c|c|c|c|c|}
\hline Treatments & Ginning & Fiber & Micronaire & Seed \\
\hline & out turn & length & value $\left(10^{-6} \mathrm{~mm}\right.$ & index \\
\hline & $(\%)$ & $(\mathbf{m m})$ & inch $^{-1}$ ) & (g) \\
\hline \multicolumn{5}{|c|}{ Main plot: Spacing (row $\times$ plant) } \\
\hline S1: $67.5 \mathrm{~cm} \times 10 \mathrm{~cm}$ & 34.2 & 23.7 & 4.1 & 6.2 \\
\hline S2: $67.5 \mathrm{~cm} \times 15 \mathrm{~cm}$ & 34.4 & 23.9 & 4.2 & 6.3 \\
\hline S3: $67.5 \mathrm{~cm} \times 22.5 \mathrm{~cm}$ & 34.7 & 24.2 & 4.3 & 6.5 \\
\hline $\mathrm{S} 4: 67.5 \mathrm{~cm} \times 30 \mathrm{~cm}$ & 35.1 & 24.4 & 4.3 & 6.7 \\
\hline $\mathrm{SE}(\mathbf{m}) \pm$ & 0.6 & 0.5 & 0.1 & 0.2 \\
\hline $\mathrm{CD}(\mathrm{P}=\mathbf{0 . 0 5})$ & NS & NS & NS & NS \\
\hline \multicolumn{5}{|l|}{ Sub plot (Nitrogen level) } \\
\hline N1: $75 \%$ of RDN & 34.3 & 23.5 & 4.2 & 6.3 \\
\hline N2: $100 \%$ of RDN & 34.6 & 24 & 4.2 & 6.4 \\
\hline N3: $125 \%$ of RDN & 34.7 & 24.2 & 4.2 & 6.5 \\
\hline N4: $150 \%$ of RDN & 34.9 & 24.6 & 4.3 & 6.6 \\
\hline $\mathrm{SE}(\mathrm{m}) \pm$ & 0.5 & 0.6 & 0.1 & 0.1 \\
\hline $\mathrm{CD}(\mathrm{P}=0.05)$ & NS & NS & NS & NS \\
\hline
\end{tabular}


Table.3 Effect of different spacing and nitrogen levels on content and uptake of nitrogen by cotton

\begin{tabular}{|c|c|c|c|c|c|}
\hline \multirow[t]{3}{*}{ TREATMENTS } & \multicolumn{4}{|c|}{ Nitrogen } & \multirow{3}{*}{$\begin{array}{c}\text { Total } \\
\text { uptake } \\
\left(\mathrm{Kg} \mathrm{ha}^{-1}\right)\end{array}$} \\
\hline & \multicolumn{2}{|c|}{ Seed } & \multicolumn{2}{|c|}{ Plant } & \\
\hline & Content & Uptake & Content & Uptake & \\
\hline & $(\%)$ & $\left(\mathrm{Kg} \mathrm{ha}^{-1}\right)$ & $(\%)$ & $\left(\mathrm{Kg} \mathrm{ha}^{-1}\right)$ & \\
\hline \multicolumn{6}{|c|}{ Main plot: Spacing (row $\times$ plant) } \\
\hline $\mathrm{S} 1: 67.5 \mathrm{~cm} \times 10 \mathrm{~cm}$ & 2.77 & 40 & 0.47 & 48.7 & 87.7 \\
\hline S2: $67.5 \mathrm{~cm} \times 15 \mathrm{~cm}$ & 2.78 & 44.5 & 0.48 & 43.8 & 87.3 \\
\hline S3: $67.5 \mathrm{~cm} \times 22.5 \mathrm{~cm}$ & 2.8 & 38.4 & 0.48 & 40.4 & 78.8 \\
\hline $\mathrm{S} 4: 67.5 \mathrm{~cm} \times 30 \mathrm{~cm}$ & 2.83 & 36.4 & 0.5 & 39.6 & 76.1 \\
\hline $\mathrm{SE}(\mathrm{m}) \pm$ & 0.07 & 1.2 & 0.01 & 1.2 & 2.1 \\
\hline $\mathrm{CD}(\mathbf{P}=\mathbf{0 . 0 5})$ & NS & 4.2 & NS & 4.1 & 7.4 \\
\hline \multicolumn{6}{|c|}{ Sub plot (Nitrogen level) } \\
\hline N1: $75 \%$ of RDN & 2.6 & 32.3 & 0.46 & 36.7 & 66.5 \\
\hline N2: $100 \%$ of RDN & 2.77 & 38.5 & 0.47 & 41.4 & 79.2 \\
\hline N3: $125 \%$ of RDN & 2.87 & 44.2 & 0.49 & 45.3 & 90.5 \\
\hline N4: $150 \%$ of $\mathrm{RDN}$ & 2.93 & 44.3 & 0.51 & 48 & 94 \\
\hline $\mathbf{S E}(\mathbf{m}) \pm$ & 0.05 & 1.2 & 0.01 & 1.3 & 1.6 \\
\hline $\mathrm{CD}(\mathrm{P}=0.05)$ & 0.16 & 3.6 & NS & 3.8 & 4.8 \\
\hline
\end{tabular}

Table.4 Effect of spacing and nitrogen application on available status of $\mathrm{N}, \mathrm{P}$ and $\mathrm{K}$ in soil after harvest of crop

\begin{tabular}{|c|c|c|c|}
\hline Treatments & $\mathbf{N}$ & $\mathbf{P}$ & $\mathbf{K}$ \\
\hline & $\left(\mathrm{kg} \mathrm{ha}^{-1}\right)$ & $\left(\mathrm{kg} \mathrm{ha}^{-1}\right)$ & $\left(\mathrm{kg} \mathrm{ha}^{-1}\right)$ \\
\hline \multicolumn{4}{|c|}{ Main plot: Spacing (row $\times$ plant) } \\
\hline $\mathrm{S} 1: 67.5 \mathrm{~cm} \times 10 \mathrm{~cm}$ & 127.5 & 10 & 401.8 \\
\hline $\mathrm{S} 2: 67.5 \mathrm{~cm} \times 15 \mathrm{~cm}$ & 129.8 & 10.1 & 402.9 \\
\hline S3: $67.5 \mathrm{~cm} \times 22.5 \mathrm{~cm}$ & 131 & 10.6 & 404.3 \\
\hline $\mathrm{S} 4: 67.5 \mathrm{~cm} \times 30 \mathrm{~cm}$ & 132.5 & 11 & 407.7 \\
\hline $\mathbf{S E}(\mathbf{m}) \pm$ & 0.6 & 0.2 & 1.2 \\
\hline $\mathrm{CD}(\mathbf{P}=0.05)$ & 2.2 & NS & NS \\
\hline \multicolumn{4}{|c|}{ Sub plot (Nitrogen level) } \\
\hline N1: $75 \%$ of RDN & 125.5 & 9.8 & 405.5 \\
\hline N2: $100 \%$ of $\mathrm{RDN}$ & 129.2 & 10.5 & 405.1 \\
\hline N3: $125 \%$ of RDN & 132.7 & 10.6 & 403.5 \\
\hline N4: $150 \%$ of $\mathrm{RDN}$ & 134.6 & 10.8 & 402.7 \\
\hline $\mathrm{SE}(\mathrm{m}) \pm$ & 0.8 & 0.4 & 1.6 \\
\hline $\mathrm{CD}(\mathrm{P}=\mathbf{0 . 0 5})$ & 2.3 & NS & NS \\
\hline
\end{tabular}




\section{Fig.1}

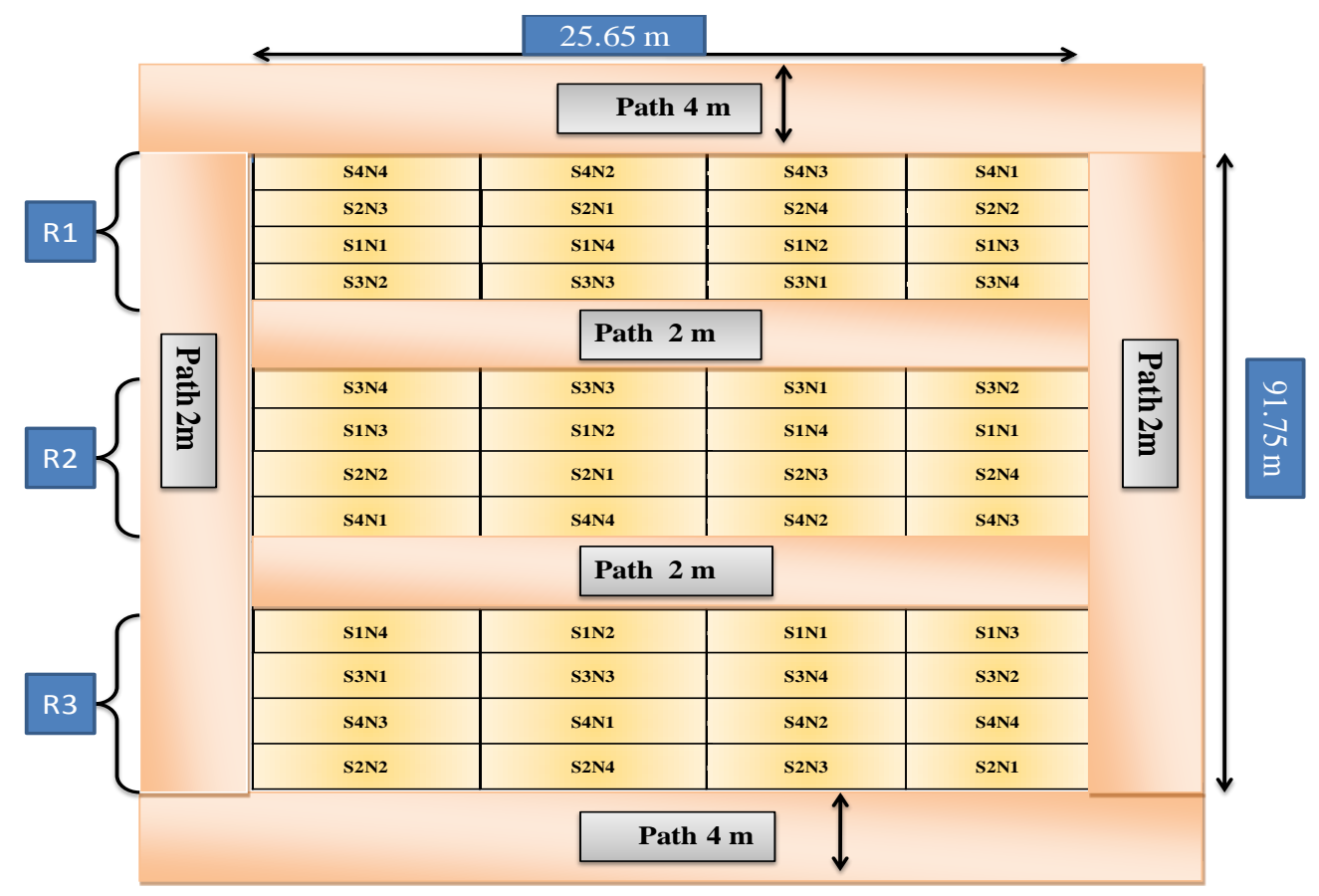

The maximum nitrogen uptake in plant was recorded at application of $150 \% \mathrm{RD}$ which was at par with $125 \% \mathrm{RD}$ of nitrogen but significant higher than $75 \%$ RD and $100 \%$ $\mathrm{RD}$ of nitrogen. The spacing of $67.5 \mathrm{~cm} \times 10$ $\mathrm{cm}$ recorded significantly higher total nitrogen uptake in cotton plant as compare to $67.5 \mathrm{~cm} \times 22.5 \mathrm{~cm}$ and $67.5 \mathrm{~cm} \times 30 \mathrm{~cm}$ but at par with $67.5 \mathrm{~cm} \times 15 \mathrm{~cm}$ spacing as shown in Table 3. On the other hand, total uptake of nitrogen increased significantly with increasing levels of nitrogen up to $125 \% \mathrm{RD}$ after which it remained statistically at par with $150 \% \mathrm{RD}$ of nitrogen. This may be attributed to availability of more nitrogen leading to higher dry matter production. Total uptake of nitrogen was maximum with $150 \%$ $\mathrm{RD}$ of nitrogen. These results are corroborative with the findings of Katkar et al., (2000) and Das and Reddy (2009).

\section{Nutrient status of soil}

Available nutrient status data of nitrogen $(\mathrm{N})$, phosphorus $(\mathrm{P})$ and potassium $(\mathrm{K})$ in soil after harvest of crop is elucidated in Table 4. The perusal of data revealed that available nitrogen in soil after harvest of crop was influenced significantly by plant geometry.

The maximum available nitrogen $(132.5 \mathrm{~kg}$ $\mathrm{ha}^{-1}$ ) in soil was found in spacing of $67.5 \mathrm{~cm}$ $\times 30 \mathrm{~cm}$ which was at par with spacing of $67.5 \mathrm{~cm} \times 22.5 \mathrm{~cm}\left(131 \mathrm{~kg} \mathrm{ha}^{-1}\right)$ but significantly higher than narrow spacing of $67.5 \mathrm{~cm} \times 10 \mathrm{~cm}$ and $67.5 \mathrm{~cm} \times 15 \mathrm{~cm}$. It was because of less plant population in wider spacing which results in higher available nitrogen in soil but available $\mathrm{P}$ and $\mathrm{K}$ in soil were not affected by different spacing. These results are confirmed with Jat et al., (2013) and Shukla et al., (2014).However, application of $125 \%$ recommended dose of nitrogen exhibited significantly higher available $\mathrm{N}$ in soil over application of $75 \%$ $\mathrm{RD}$ and $100 \% \mathrm{RD}$ of nitrogen, but it was statistically at par with $150 \%$ RD of nitrogen levels. While, the different spacing and nitrogen doses did not influence the available phosphorus and potassium in the soil. This 
improvement in soil fertility status might be attributed to direct addition of nutrients to the available pool of soil. Similar results are also reported by Jat et al., (2014).

In conclusion the results of experiment stated that the quality characters of cotton variety $\mathrm{H}$ 1098 (i) viz; ginning out turn, fiber length, micronaire value, and seed index were not affected significantly by different spacing and nitrogen rate application. Similarly, nitrogen content in seed and plant was also not affected due to different spacing but total uptake was maximum with spacing of 67.5 $\mathrm{cm} \times 10 \mathrm{~cm}$. but, increase in nitrogen doses can increase the nitrogen uptake in plant, seed and total uptake up to $125 \%$ RD of nitrogen. The available nitrogen in soil was higher under $67.5 \mathrm{~cm} \times 30 \mathrm{~cm}$ spacing. However, no significant variation in available $\mathrm{P}$ and $\mathrm{K}$ in soil was observed in different spacing treatments. Likewise, available nitrogen differed significantly under different nitrogen doses, but had no significant result were obtained in relation to available Phosphorus and potassium in soil.

\section{References}

Ahmad, A.U.H., Ali, R., Zamir, S.I. and Mahmood, N. 2009.Growth, yield and quality performance of cotton cultivar BH-160 (Gossypium hirsutum L.) as influenced by different plant spacing. $J$. Anim. \& Plant Sci., 19(4): 189-192.

Bharathi, S., Rao, G.M.V.P., Kumari, R. and Reddy, V.C. 2012. Influence of plant geometry and nitrogen levels on performance of cotton hybrids under rainfed conditions in vertisols of Andhra Pradesh. J. Cotton Res. Dev., 26(2): 204-206.

Das M. D. and Reddy, M. G. 2009.Influence of level and frequency of nitrogen application on nutrient uptake, yield and economics of Bt cotton hybrids. J. Res.
ANGRAU., 37(2): 50-52.

Devraj, Bhatoo, M.S., Duhan, B.S. and Jain, P.P. 2011. Effect of crop geometry and fertilizer levels on seed cotton yield and nutrient uptake of $\mathrm{Bt}$ cotton under irrigated conditions. J. Cotton Res. Dev., 25(2): 176-180.

Dhillon, R.N., Chabra, K.L. and Punia, S.S. 2006. Effect of crop geometry and integrated nutrient management on fibre quality and nutrient uptake by cotton crop. J. Cotton Res. Dev., 20(2): 221223.

Jackson, M.L. (1973). Soil Chemical Analysis. Prentice Hall of India Pvt. Ltd., New Delhi.

Jagtap, D.N. 2008. Response of desi cotton hybrid to plant densities and nitrogen levels. M.Sc. (Agri.) thesis MAU, Parbhani.

Jat, R.D. and Nanwal, R.K. 2013. Growth, nutrient uptake and productivity of $\mathrm{Bt}$ cotton (Gossypium hirsutum L.) influenced by spacing and nutrient levels. Crop. Res., 45(3): 248-252.

Jat, R.D., Nanwal, R.K. and Kumar, P. 2014. Productivity, quality and available nutrient of $\mathrm{Bt}$ cotton (Gossypium hirsutum L.) under different spacing and nutrient levels. J. cotton Res. Dev., 28(1): 70-73.

Katkar, R.N., Turkhede, A.B., Wankhde, S.T. and Solanke, V.M. 2000. Studies on the agronomic requirement of promising cotton hybrids. Crop Res., 19(3): 525526.

Malik, K., Mehta, A. K., Thakral, S. K., \& Abhilash. (2019). Crop geometry and nitrogen management impacts on cotton cultivar H-1098 (i) productivity. Indian Journal of Agricultural Sciences, 89(11), 61-65.

Olsen, S.R., Cole, V.C., Watanabe, F.S. and Dean, L.A. (1954). Estimation of available phosphorus in soils by extraction with sodium bicarbonate. 
United States Department of Agriculture Circle, 939, 621-628.

Paslawar, A.N., Deotalu, A.S., Deshmukh, S.B. and Bhongle, S.A. 2014. Productivity of arboretum cotton hybrids and quality as influenced by plant spacing and fertilizer management. Periodic Res., 3(1): 1416.

Piper, C.S. (1966). Soil and plant analysis. Hans Publisher, Bombay

Richards, L. A. (1954). Diagnosis and improvement of saline and alkaline soils. USDA Hand Book No.60, Washington, D.C.

Sharma, J.K., Upadhyay, A., Mishra, U.S., Khamparia, S.K. and Mandloi, K.C. 2001. Effect of spacing and fertility levels on growth and yield of hirsutum genotypes. J. Cotton Res. Dev., 15(2): 151-153.

Shekar, K. Ramana, M.V., Devi, S.S. and Kumari, S.R. 2012. Effect of spacing and canopy management on yield, quality and economics of Bt cotton. $J$. Cotton Res. Dev., 26(2): 209-211.

Shukla, U.N., Khakare, M.S., Singh, S. and Verma, S.K. 2014. Effect of crop geometry and fertility levels on growth, yield and residual nutrient of cotton (Gossypium hirsutum) hybrids under rainfed condition. Indian J. Agric. Sci., 84(6): 780-783.

Subbiah, B.V. and Asija, G.L. (1956). A rapid procedure for estimation of available nitrogen in soils. Current Science, 25, 259-260.

\section{How to cite this article:}

Kapil Malik, A. K. Mehta and Thakra, S. K. 2021. Quality Parameters, Nitrogen Content and Uptake of Cotton Cultivar H-1098(i) and Nutrient Status of Soil Influence by Different Spacing and Nitrogen Application. Int.J.Curr.Microbiol.App.Sci. 10(01): 3058-3066. doi: https://doi.org/10.20546/ijcmas.2021.1001.356 